\title{
Castor Leaves-Based Biochar for Adsorption of Safranin from Textile Wastewater
}

\author{
Muhammad Suleman ${ }^{1,2,+}$, Muhammad Zafar ${ }^{3,+}{ }^{+}$, Ashfaq Ahmed ${ }^{4,5,+}+\mathbb{C}$, Muhammad Usman Rashid ${ }^{6, *}$, \\ Sadiq Hussain ${ }^{2}$, Abdul Razzaq ${ }^{5}$, Nur Atikah Mohidem ${ }^{7}$, Tahir Fazal ${ }^{1,5}$, Bilal Haider ${ }^{6}$ and Young-Kwon Park ${ }^{4, *}$
}

1 Department of Chemical Engineering, Khwaja Fareed University of Engineering and Information Technology, Rahim Yar Khan 64200, Pakistan; muhammad.suleman@kfueit.edu.pk (M.S.); tahir.fazal@kfueit.edu.pk (T.F.)

2 Department of Chemical Engineering, NFC Institute of Engineering \& Technology, Multan 60000, Pakistan; sadiqhussain@nfciet.edu.pk

3 Institute of Energy and Environmental Engineering, University of the Punjab, Lahore 54590, Pakistan; zaffarsher@gmail.com

4 School of Environmental Engineering, University of Seoul, Seoul 02504, Korea; ashfaqengr97@gmail.com

5 Department of Chemical Engineering, COMSATS University Islamabad, Lahore Campus, Raiwind Road, Lahore 54000, Pakistan; abdulrazzaq@cuilahore.edu.pk

6 Institute of Chemical Engineering \& Technology, Quaid-e-Azam Campus, University of the Punjab, Lahore 54590, Pakistan; bilal.icet@pu.edu.pk

7 Department of Biological and Agricultural Engineering, Faculty of Engineering, Universiti Putra Malaysia, Serdang 43400, Selangor, Malaysia; nuratikahmohidem@gmail.com

* Correspondence: usmanrashid.icet@pu.edu.pk (M.U.R.); catalica@uos.ac.kr (Y.-K.P.)

$\dagger$ First co-authors with equal contributions.

Citation: Suleman, M.; Zafar, M. Ahmed, A.; Rashid, M.U.; Hussain, S.; Razzaq, A.; Mohidem, N.A.; Fazal, T.; Haider, B.; Park, Y.-K. Castor Leaves-Based Biochar for Adsorption of Safranin from Textile Wastewater. Sustainability 2021, 13, 6926. https:// doi.org/10.3390/su13126926

Academic Editor: Alessio Siciliano

Received: 18 May 2021

Accepted: 14 June 2021

Published: 19 June 2021

Publisher's Note: MDPI stays neutral with regard to jurisdictional claims in published maps and institutional affiliations.

Copyright: (C) 2021 by the authors Licensee MDPI, Basel, Switzerland. This article is an open access article distributed under the terms and conditions of the Creative Commons Attribution (CC BY) license (https:/ / creativecommons.org/licenses/by/ $4.0 /)$.
Abstract: The prospect of synthesizing biochar from agricultural wastes or by-products to utilize them as a promising adsorbent material is increasingly gaining attention. This research work focuses on synthesizing biochar from castor biomass (CBM) and evaluating its potential as an adsorbent material. Castor biomass-based biochar (CBCs) prepared by the slow pyrolysis process at different temperatures $\left(\mathrm{CBC} 400{ }^{\circ} \mathrm{C}, \mathrm{CBC} 500{ }^{\circ} \mathrm{C}\right.$, and $\mathrm{CBC} 600^{\circ} \mathrm{C}$ for $1 \mathrm{~h}$ ) was investigated for the adsorption of textile dye effluents (safranin). The pyrolysis temperature played a key role in enhancing the morphology, and the crystallinity of the biochar which are beneficial for the uptake of safranin. The CBC600 adsorbent showed a higher safranin dye removal $(99.60 \%)$ and adsorption capacity $(4.98 \mathrm{mg} / \mathrm{g})$ than CBC500 (90.50\% and $4.52 \mathrm{mg} / \mathrm{g})$, CBC400 (83.90\% and $4.20 \mathrm{mg} / \mathrm{g})$, and castor biomass (CBM) $(64.40 \%$ and $3.22 \mathrm{mg} / \mathrm{g})$. Adsorption data fitted better to the Langmuir isotherm model than to the Freundlich isotherm model. The kinetics of the adsorption process was described well using the pseudo-second-order kinetic model. The study on the effect of the contact time for the adsorption process indicated that for $\mathrm{CBC} 600,80 \%$ dye removal occurred in the first $15 \mathrm{~min}$ of the contact time. After three regeneration cycles, CBC600 exhibited the highest dye removal efficiency $(64.10 \%)$, highlighting the enhanced reusability of CBCs. The crystalline patterns, functional binding sites, and surface areas of the prepared CBCs (CBC400, CBC500, CBC600) were characterized by $\mathrm{X}$-ray diffraction, Fourier transform infrared spectroscopy, and Brunauer-Emmett-Teller surface area measurements, respectively.

Keywords: adsorption; biochar; castor biomass; safranin dye; wastewater treatment

\section{Introduction}

Rapid population growth and industrialization have led to an increase in energy demands and environmental problems and reduced clean water sources [1,2]. The use of chemicals for various processes in industry and effluents from such industries are posing massive threats to public health and are contributing to the increased shortage of potable water [3]. Industries using dyes during production (e.g., clothes, printing, food, and paper industries) discharge enormous amounts of dyes annually; approximately $2.8 \times 10^{5}$ tons 
of textile dyes annually are released in industrial effluents worldwide [4]. Untreated effluents lead to the contamination of groundwater, surface water, and even irrigated soils. The presence of dyes at lower concentrations ( $>1 \mathrm{ppm})$ is exceptionally visible and adversely affects the aquatic environment by restricting light infiltration. These dyes present in the water can be carcinogenic, teratogenic, mutagenic, and harmful to aquatic life and human health. The environmental protection agencies and legislation regarding the permissible limit of dyes in wastewater streams require the elimination of these potent sources before being discharged [5-7].

Different physicochemical treatment processes have been applied to remove dyes from textile wastewater (TWW), such as adsorption ion exchange, reverse osmosis, precipitation, photodegradation, ozonation and other chemical oxidation, membrane bioreactors, electrolysis, electrodialysis, foam flotation, photocatalysis, and filtration [8]. These treatment methods are expensive, have intricate designs, high capital costs, high maintenance costs, and high operating costs, and produce massive amounts of sludge that causes problems in being discarded [9]. On the other hand, the adsorption process is more acknowledged, comprehensive, and used extensively to eliminate dyes owing to its operational flexibility, implementation, cost-effectiveness, eco-friendliness, and excellent removal efficiency [10]. This technology employs adsorbent materials for the uptake of contaminants, such as dyes, from TWW [11,12].

Numerous adsorbents have been reported: coir pith [13]; red mud [14]; neem leaf [15]; waste organic peel and activated sludge [16]; minerals [17]; tree fern [18]; peat [19]; zeolites and metal-organic frameworks (MOFs) [20]; pulp and paper sludge and castor leaves [21]; red clay and activated carbon [22]. Activated carbon (AC) has frequently been used to remove dyes from wastewater. On the other hand, the high synthesis cost of AC and its preparation requires the use of bituminous coal, animal residue, and different plants demanding high temperatures and new activation processes [23]. Therefore, it is essential to replace expensive AC with low-cost adsorbents.

Recently, biomass-based biochar has attracted attention for the remediation of different dyes from wastewater for its renewable and abundantly available nature, economic feasibility, and effectiveness [23]. Biochar (BC) can be prepared from different types of biomass, such as organic waste, crops, woody materials, algae, deoiled cakes, seed covers, castor leaves, and aquatic weed species [24]. Research on the synthesis of biochar-based adsorbents for the uptake of metals and dyes has increased enormously [24-26]. The favourable properties exhibited by biochar including the high surface area, highly porous structure, hollow network structure, and enhanced ion exchange capacity make it an attractive choice for adsorption applications [24]. These materials are considered heterogeneous carbon-based materials formed by the pyrolysis process in the absence of oxygen [26]. Several factors influence the efficiency, morphology, and potential of biochar, including the heating temperature, residence time, and heating rate [26].

Recently, the use of castor seeds for castor oil production has increased because of their applications in beauty products and biofuels. Consequently, the cultivation of castor crops has increased, and its processing results in the accumulation of huge amounts of dry biomass residue $\left(0.8\right.$ to $\left.10 \mathrm{Mg} \mathrm{ha}^{-1}\right)$ in terms of stalks and leaves $[27,28]$. In this study, castor leaf-based biochar was developed for the adsorption of dyes from waste effluents, such as textile wastewater, to provide beneficial use of these residues. Safranin, which is extensively used in industry for multiple applications, such as staining leather, cotton, and wool, and in paint industries, was used as a model cationic dye. The influence of different parameters such as the $\mathrm{pH}$, initial dye concentration, dosage, and contact time on dye removal (\%) and $\mathrm{CBC}$ adsorption capacity was also investigated along with the influence of the pyrolysis temperature on the adsorption capacity of adsorbents. Moreover, the adsorption data were examined with various adsorption isotherm models and kinetic models. Adsorbent characterization was performed to determine the influence of the pyrolysis temperature on the morphology, crystallinity, surface area, and presence of functional groups. 


\section{Materials and Methods}

\subsection{Collection and Pretreatment of Castor Biomass}

Castor biomass (CBM) was procured from the rural areas of Rahim Yar Khan District, Pakistan, and washed with distilled water to remove the suspended impurities. The biomass was dried overnight in an oven at $80^{\circ} \mathrm{C}$ followed by crushing and grinding to pass through a 100 mesh sieve (US Tyler) to obtain a uniform particle size of $150 \mu \mathrm{m}$.

\subsection{Preparation of Biochar}

The pyrolysis of $\mathrm{CBM}$ was conducted in a fixed bed reactor to produce biochar at the desired pyrolysis temperatures of $400{ }^{\circ} \mathrm{C}, 500^{\circ} \mathrm{C}$, and $600^{\circ} \mathrm{C}$. The biomass residence time was maintained for $1 \mathrm{~h}$, and the heating rate was $20^{\circ} \mathrm{C} / \mathrm{min}$ for all experiments [29]. A stream of pure $\mathrm{N}_{2}$ gas $(1000 \mathrm{~mL} / \mathrm{min})$ was passed through the reactor to provide an inert environment during the pyrolysis process. After the experiments were complete, the residues were left in the system to cool down to ambient temperature. The prepared biochars were then ground and sieved to achieve a particle size in the range of $0.075-0.710 \mathrm{~mm}$ and were dried overnight at $80^{\circ} \mathrm{C}$.

\subsection{Characterization of $C B C s$}

The $\mathrm{CBC}$ s were characterized using a range of techniques. X-ray diffraction (XRD, Panaytical $X^{\prime}$ pert pro) was performed to investigate the crystallinity. The presence of various functional groups in the adsorbent samples was examined by Fourier transform infrared (FTIR, Thermo-Nicolet 6700) spectroscopy. The surface area and pore size of the CBCs were measured using the Brunauer-Emmet-Teller (BET) method. The $\mathrm{N}_{2}$ adsorption/desorption on the surface of the adsorbent samples was measured at $77 \mathrm{~K}$. The $\mathrm{pH}$ drift method was followed to determine the point zero charge (PZC), as reported elsewhere [23].

\subsection{Preparation of the Dye Solution}

Safranin dye (basic dye, $\mathrm{C}_{20} \mathrm{H}_{19} \mathrm{ClN}_{4}$, and molar mass $350.85 \mathrm{~g} / \mathrm{mole}$, Sigma Aldrich, Darmstadt Germany was procured and used. A $1000 \mathrm{mg}$ sample of safranin dye was dissolved in $1 \mathrm{~L}$ of distilled water to prepare a stock solution of $1000 \mathrm{ppm}$. The stock solution was diluted to the desired concentrations. A UV-visible spectrophotometer was used to measure the absorbance of safranin dye at $\lambda=518 \mathrm{~nm}$ [11]. Figure 1 presents the safranin structure.<smiles>Cc1cc2nc3c(C)c(N)ccc3[n+](-c3ccccc3)c2cc1N</smiles>

Figure 1. Safranin dye structure.

\subsection{Experimental Setup Design}

The adsorption experiments were conducted in batch mode to study the uptake of safranin dye on the prepared biochar-based adsorbents. The effects of various parameters on the adsorption capacity were investigated using the one factor-one time approach, including $\mathrm{pH}(2-10)$, contact time (5-240 min), initial dye concentration (1-100 mg/L), and adsorbent dose $(0.05,0.10,0.15,0.20$, and $0.25 \mathrm{~g})$ at room temperature conditions [30]. In each experimental run, $100 \mathrm{mg}$ of adsorbent was placed in $100 \mathrm{~mL}$ of a dye solution 
in an Erlenmeyer flask. The solution was shaken on an orbital shaker (SK-O330-Pro) at $200 \mathrm{rpm}$ for $4 \mathrm{~h}$ to achieve equilibrium between the adsorbate and adsorbent. The adsorbent particles were separated using a centrifuge (CFM-1723, Sajid Engineering Works) at $3600 \mathrm{rpm}$ for $10 \mathrm{~min}$ [31]. The absorbance of the supernatant samples was determined using a UV-visible spectrophotometer (Peak Instruments C-7200S) at a wavelength of $518 \mathrm{~nm}$. The dye removal (\%) and adsorption capacities of the CBCs were determined using the final concentration of safranin in an aqueous solution. Equations (1) and (2) were used to determine the dye removal (\%) and adsorption capacities, respectively [32,33].

$$
\begin{aligned}
R(\%) & =\left(C_{o}-C_{e}\right) \times \frac{100}{C_{o}} \\
q & =\left(C_{o}-C_{e}\right) \frac{V}{W}
\end{aligned}
$$

where $R$ represents the dye removal $(\%) ; C e(\mathrm{mg} / \mathrm{L})$ and $C_{0}(\mathrm{mg} / \mathrm{L})$ refer to the dye concentration at equilibrium and the initial dye concentration, respectively; $q(\mathrm{mg} / \mathrm{g}), V$ $(L)$, and $W(\mathrm{~g})$ are the adsorption capacity, volume of dye solution, and adsorbent mass, respectively. The adsorption kinetics was studied to determine the rate-limiting step. This task was performed by finding the safranin adsorption rate as a function of time. The amount of safranin adsorbed at any time $\mathrm{q}_{\mathrm{t}}(\mathrm{mg} / \mathrm{g})$ was calculated using Equation (3) [28].

$$
q_{t}=\left(C_{o}-C_{t}\right) \frac{V}{W}
$$

where $C_{t}(\mathrm{mg} / \mathrm{L})$ is the concentration of dye at any time $t$.

\subsection{Point of Zero Charge}

The $\mathrm{pH}$ drift method was used to determine the point of zero charge for all adsorbents. Briefly, each $100 \mathrm{~mL}$ conical flask was filled with $20 \mathrm{~mL}$ of different $\mathrm{pH}$ solutions from $\mathrm{pH}$ 2 to 11 . The initial $\mathrm{pH}\left(\mathrm{pH}_{0}\right)$ of the conical flasks was adjusted by the stepwise addition of $0.1 \mathrm{M} \mathrm{HCl}$ or $\mathrm{NaOH}$ solutions. A $0.10 \mathrm{~g}$ sample of the adsorbents was added to each conical flask and shaken for $24 \mathrm{~h}$ to maintain the $\mathrm{pH}$ of the solution. The supernatant of the solution was used to measure the final $\mathrm{pH}\left(\mathrm{pH}_{f}\right)$. The change in $\mathrm{pH}(\Delta p H)$ was calculated using Equation (4) [23]. A graph of $p H_{0}$ vs. $\Delta p H$ was plotted, as shown in Figure 2. The $\mathrm{pH}$ at a point of zero charge $\left(\mathrm{pH}_{\mathrm{PZC}}\right)$ was determined at the inflection point. The $\mathrm{pHpzc}$ point for the $\mathrm{CBC}$ adsorbent was found at approximately $\mathrm{pH}$ 6, and $\mathrm{pH} 5$ for $\mathrm{CBM}$.

$$
\Delta p H=p H_{0}-p H_{f}
$$

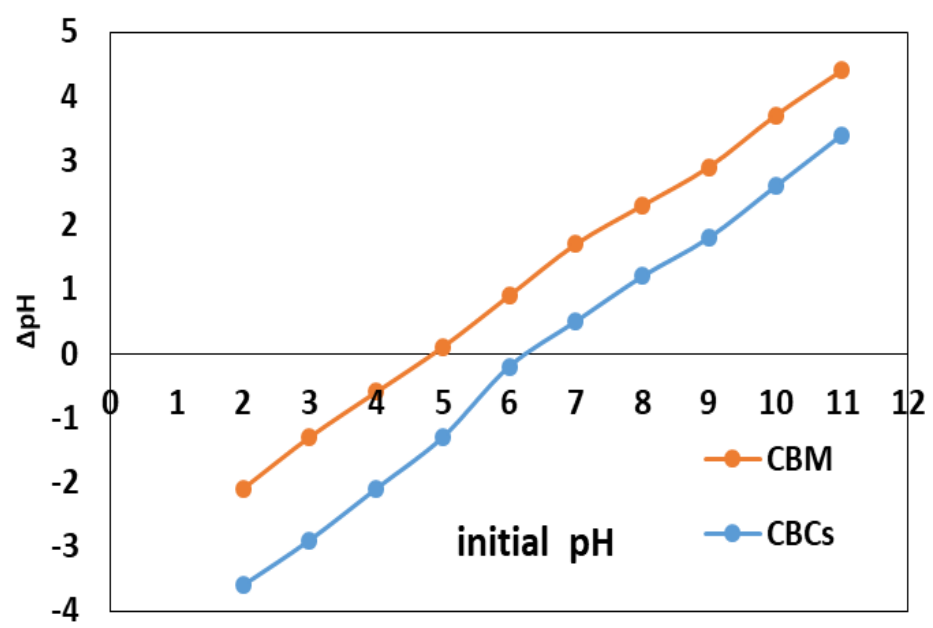

Figure 2. Point of zero charge for CBM and CBCs. 


\section{Results and Discussion}

\subsection{Characterization of $C B M$ and $C B C s$}

3.1.1. BET and Microscopic Analysis

The surface area and pore size of CBCs and CBM were analyzed using the BET apparatus. The BET results indicate that the pyrolysis temperature has a strong influence on the surface area of the adsorbent. As described in Table 1, the surface area increased with increasing pyrolysis temperature. Therefore, CBC600 and CBC500 exhibited a higher surface area of $58.94 \mathrm{~m}^{2} / \mathrm{g}$ and $46.32 \mathrm{~m}^{2} / \mathrm{g}$, respectively, compared to the adsorbents pyrolyzed at lower temperatures, as mentioned in Table 1. The application of a higher pyrolysis temperature and longer pyrolysis times resulted in biochars with a higher surface area and porosity [34]. An adsorbent with a higher surface area and porosity leads to a higher exposed area available for the adsorption of an adsorbate, providing more opportunities for the uptake of safranin dye [23,27]. Similar results were reported by Fazal et al. [23] for macroalgae and coal-based biochar synthesis. An increasing trend in the surface area with the shift in the pyrolysis temperature was observed.

Table 1. BET results for various adsorbents.

\begin{tabular}{cccc}
\hline Adsorbent & Pore Size & Pore Volume & Surface Area \\
\hline Unit & $\mathrm{nm}$ & $\mathrm{cc} / \mathrm{g}$ & $\mathrm{m}^{2} / \mathrm{g}$ \\
CBM & 1.12 & 0.021 & 11.51 \\
CBC400 & 2.56 & 0.024 & 31.65 \\
CBC500 & 3.49 & 0.049 & 46.32 \\
CBC600 & 8.26 & 0.111 & 58.94 \\
\hline
\end{tabular}

\subsubsection{XRD Analysis}

$\mathrm{XRD}$ is useful for determining the crystallinity and morphological features regarding the pattern of adsorbents. The XRD pattern of the spent adsorbents was recorded in the $20^{\circ}-80^{\circ} 2 \theta$ range (Figure 3 ). No sharp peaks were observed in the diffraction profiles, indicating the dominance of an amorphous structure. On the other hand, the peaks observed at $25.7^{\circ}, 25.9^{\circ}, 26^{\circ}$, and $26.9^{\circ} 2 \theta$ revealed the presence of a crystalline carbonaceous structure, such as graphite $[23,28]$. Moreover, with increasing pyrolysis temperature, a shift in the peak for the graphite carbon structure was observed from $25.9^{\circ}$ to $26.9^{\circ}$, showing that the higher pyrolysis temperature induced a well-formed graphite structure. A study on the influence of the temperature on the morphology of a cotton stalk during pyrolysis indicated that with increasing temperature, the conversion of an amorphous carbon structure to a graphite microcrystalline structure occurs [35].

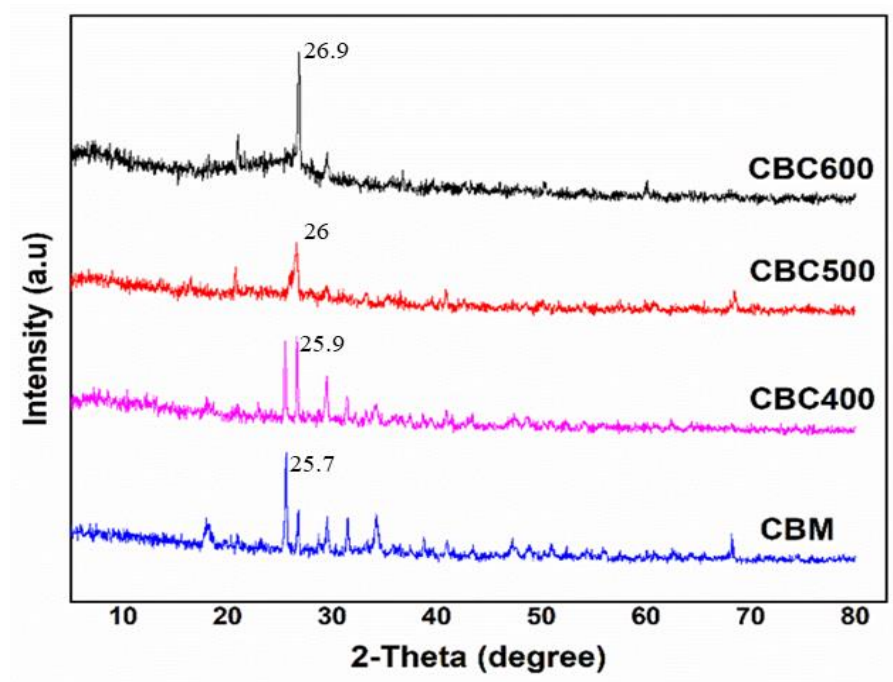

Figure 3. XRD patterns of $\mathrm{CBM}$ and $\mathrm{CBCs}$. 


\subsubsection{FTIR Spectrum}

FTIR (Thermo-Nicolet 6700) spectroscopy was performed to determine the functional groups present in the CBM and CBC samples, as shown in Figure 4. The broader peaks of the stretching hydroxyl $(\mathrm{O}-\mathrm{H})$ groups appeared around $3200-3300 \mathrm{~cm}^{-1}$ for CBM and $\mathrm{CBC} 400$. The presence of the $\mathrm{OH}$ group can be attributed to the aldehydes, phenols, or alcoholic compounds present in CBM. On the other hand, with increasing pyrolysis temperature $\left(>400{ }^{\circ} \mathrm{C}\right)$, the IR peaks related to the $\mathrm{O}-\mathrm{H}$ stretching band disappeared from the spectrum for the CBC500 and CBC600 samples. The disappearance of these peaks indicates that the dehydration of biomass at higher temperatures will release larger amounts of water [35]. Similar results have been reported [21,35]. Similarly, the C-H stretching peak in the region of $2800-2900 \mathrm{~cm}^{-1}$ was observed for CBM and CBC400, but CBC500 and CBC600 exhibited no peak dedicated to the degradation of alkyl C-H bonds at such higher pyrolysis temperatures [35]. At pyrolysis temperatures higher than $400{ }^{\circ} \mathrm{C}$, cellulose and hemicellulose degradation occurs in a more distinct manner [35]. The small peak at $1630 \mathrm{~cm}^{-1}$ in CBM and CBC400 was assigned to either carbonyl $(\mathrm{C}=\mathrm{O})$ group of ketones or aldehydes [36]. The bands at $1510-1530 \mathrm{~cm}^{-1}$ in CBM and CBC400 were attributed to the aromatic $(\mathrm{C}=\mathrm{C})$ vibrating groups [37], which break down at high pyrolysis temperatures in $\mathrm{CBC} 500$ and $\mathrm{CBC} 600$. The broader peaks in the range of 1380 $1480 \mathrm{~cm}^{-1}$ for CBM and CBC400 indicate C-H deformation in the aromatic components of the samples and possibly due to the $\mathrm{C}=\mathrm{C}$ vibration [38].

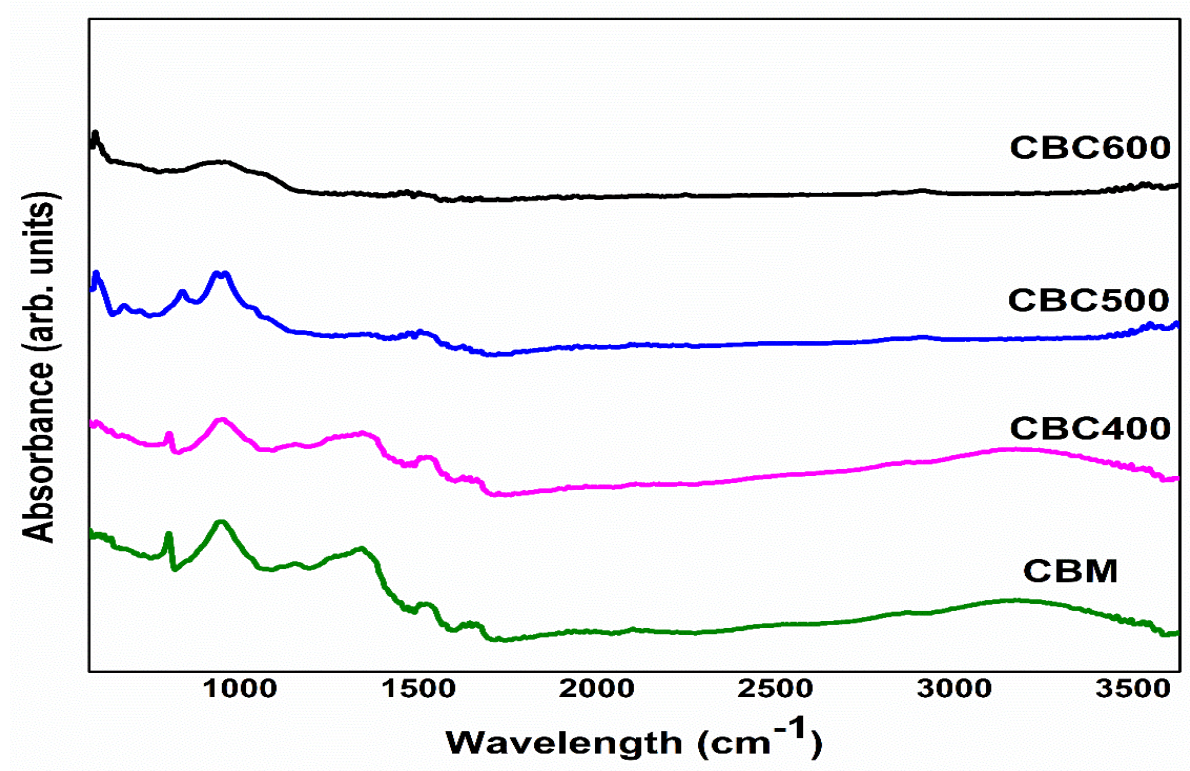

Figure 4. FTIR spectra of adsorbents.

\subsection{Effect of $p H$}

The solution $\mathrm{pH}$ strongly influences the adsorption of dyes, which is dedicated to the surface charge of adsorbents and adsorbate properties [30,39]. Batch experiments were performed using a $0.1 \mathrm{~g}$ adsorbent dosage, $4 \mathrm{~h}$ contact time, and $5 \mathrm{mg} / \mathrm{L}$ initial safranin concentration. The adsorption of safranin dye on the $\mathrm{CBC}$ adsorbents has been well described by the point zero charge studies. The $\mathrm{pHpzc}$ of $\mathrm{CBC}$ was at $\mathrm{pH} 6$ (Figure 2). At this $\mathrm{pH}$, the $\mathrm{CBC}$ surface was negatively charged. Below this $\mathrm{pH}$, the surface of the adsorbent was positively charged. At a higher $\mathrm{pH}$, the adsorption of positive safranin dye molecules increased and was favored electrostatically as the surface of the adsorbent became negatively charged. Similar trends for the increase in the adsorption capacity of adsorbents with increasing $\mathrm{pH}$ and the effect of $\mathrm{pHpzc}$ on adsorption have been reported $[30,40,41]$. Moreover, the surface charge of the $\mathrm{CBC}$ s becomes more negative with increasing $\mathrm{pH}$, thereby reducing the repulsion between the $\mathrm{CBCs}$ and safranin dye ions and increasing the 
removal efficiency. Moreover, the strong competition for adsorption sites arises between the safranin positive ions and $\mathrm{H}^{+}$at a lower $\mathrm{pH}$. At a higher $\mathrm{pH}$, this competition decreases gradually due to the decrease in the $\mathrm{H}^{+}$ion concentration.

The CBC600 adsorption capacity $\left(q_{e}\right)$ increased from 3.83 to $4.91 \mathrm{mg} / \mathrm{g}$ compared to CBM, which increased from 2.12 to $3.24 \mathrm{mg} / \mathrm{g}$, with a shift in the $\mathrm{pH}$ from 2 to 6 (Figure $5 \mathrm{~b}$ ). This is dedicated to the lower electrostatic repulsion forces between the safranin molecules and adsorbents. CBM exhibited the lowest safranin removal of $42.4 \%$ at $\mathrm{pH} 2$ and reached up to $64.9 \%$ at $\mathrm{pH}$ 6. The maximum removal efficiency was observed for CBC600 $(98.20 \%)$, compared to the other $\mathrm{CBCs}(90.04 \%$ for $\mathrm{CBC} 500$, and $83.7 \%$ for $\mathrm{CBC} 400$ at $\mathrm{pH}$ ) $)$ and reached $76.70 \%$ at $\mathrm{pH} 2$.
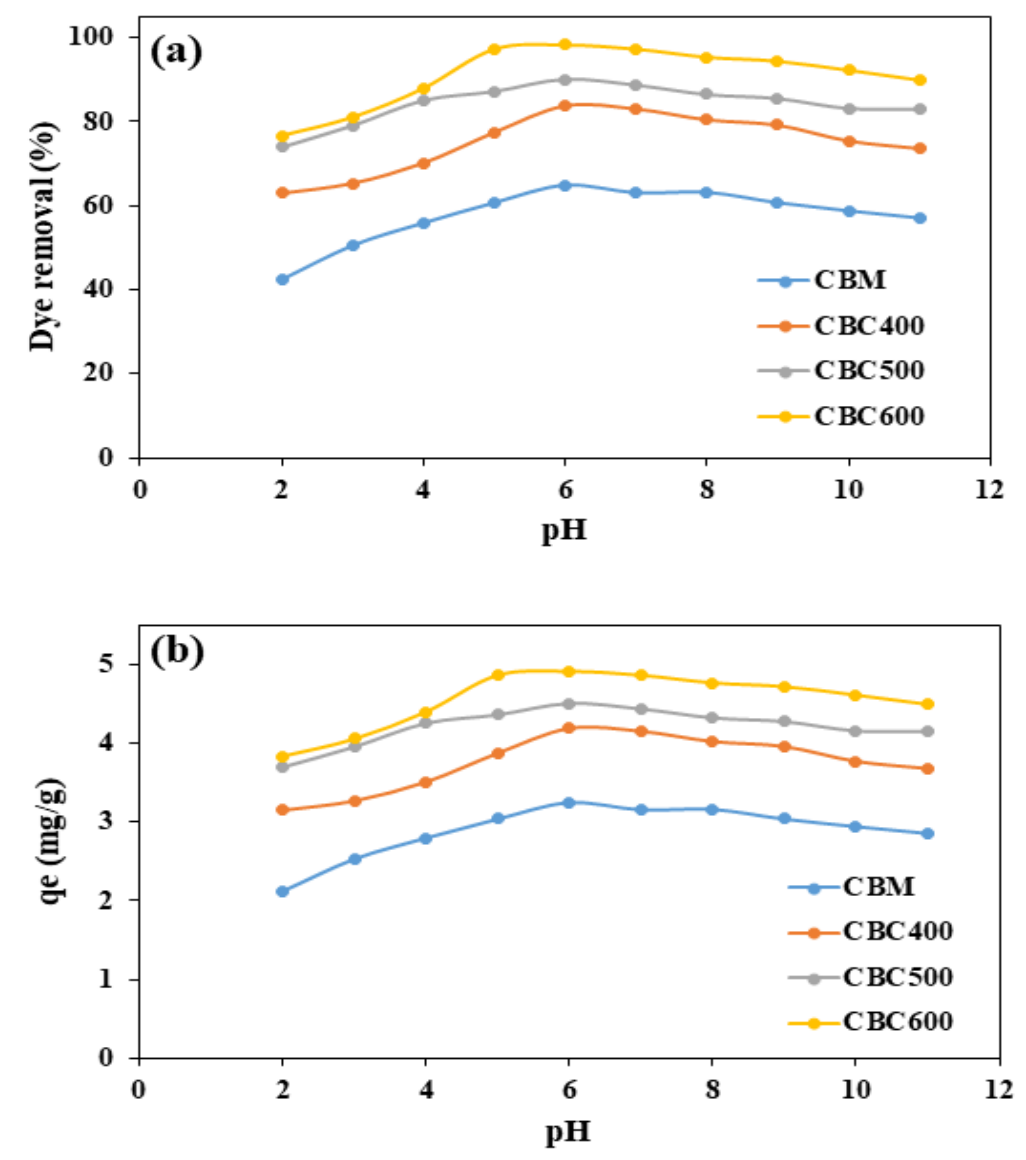

Figure 5. Effect of $\mathrm{pH}$ on (a) dye removal (\%) and (b) adsorption capacity.

\subsection{Effect of Contact Time}

The contact time is important for determining the adsorbate amount on a certain fixed adsorbent mass as a function of time [30]. Figure $6 \mathrm{a}, \mathrm{b}$ show the effect of the contact time (5-240 $\mathrm{min}$ ) on the dye removal (\%) and adsorption capacity of adsorbents, respectively. A rapid increase in the dye removal (\%) and adsorption capacity was observed at a starting time of 5-15 $\mathrm{min}$ (fast adsorption), which slowed down in 15-240 min (slow adsorption). CBC400, CBC500, and CBC600 exhibited high adsorption capacities at $90 \mathrm{~min}(3.47 \mathrm{mg} / \mathrm{g}$, $4.04 \mathrm{mg} / \mathrm{g}$, and $4.59 \mathrm{mg} / \mathrm{g}$, respectively) compared to CBM, which exhibited $2.32 \mathrm{mg} / \mathrm{g}$, and increased only slightly after $90 \mathrm{~min}$. The results show that the equilibrium time for dye removal (\%) was $120 \mathrm{~min}$ for CBC600, $120 \mathrm{~min}$ for CBC500, $150 \mathrm{~min}$ for CBC400, and $170 \mathrm{~min}$ for CBM. In $15 \mathrm{~min}$, CBC600 exhibited approximately $80 \%$ dye removal. The adsorption of safranin in the fast adsorption stage will occur on the external surface of the CBC600 adsorbent with the mechanism of the boundary layer, and the higher adsorption will be due to the higher surface area [30,39]. 

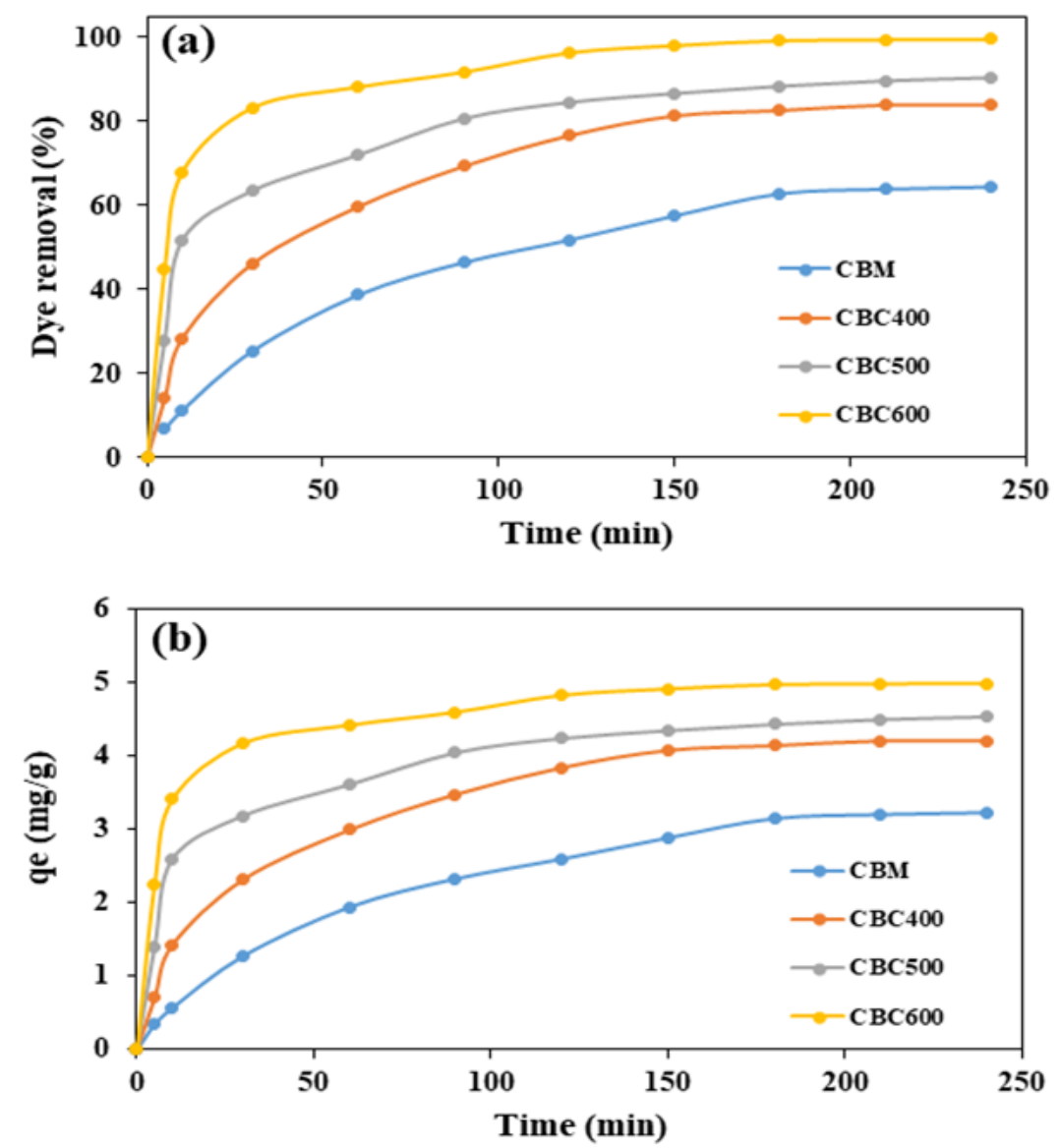

Figure 6. Effect of contact time on (a) dye removal (\%) and (b) adsorption capacity.

The higher adsorption capacity and dye removal for $\mathrm{CBC} 600$ compared to the $\mathrm{CBC} 500$, $\mathrm{CBC} 400$, and $\mathrm{CBM}$ adsorbents were dedicated to the larger average pore size, pore volume, and surface area for $\mathrm{CBC} 600$, as shown in Table 1. A study on the adsorption of methyl orange $(\mathrm{MO})$ on $\mathrm{CuO}$ and $\mathrm{NiO}$ nanoparticles provided a similar explanation for the higher adsorption capacity of $\mathrm{NiO}$ nanoparticles for $\mathrm{MO}$ adsorption than $\mathrm{CuO}$ nanoparticles. The higher adsorption capacity of $\mathrm{NiO}$ nanoparticles was dedicated to the higher surface area $\left(78.4 \mathrm{~m}^{2} / \mathrm{g}\right)$ and pore volume $\left(0.068 \mathrm{~cm}^{3} / \mathrm{g}\right)$ compared to $\mathrm{CuO}\left(6.19 \mathrm{~m}^{2} / \mathrm{g}\right.$ and $0.028 \mathrm{~cm}^{3} / \mathrm{g}$ ) [42]. A similar adsorption pattern exhibited by safranin dye in this study was reported in another study conducted on the uptake of green dye by red clay [30]. At later stages of adsorption, the adsorption sites were saturated, resulting in a lower removal efficiency. The repulsive forces start to operate between the two safranin molecules: one in the bulk phase and the other adsorbed on the surface of the adsorbent $[39,43]$. Another reason for the later slow adsorption phase was that the adsorbent needs to undergo a deeper morphology of the adsorbent. In this step, the molecular diffusion faces a higher resistance, giving rise to a second slower stage [39].

\subsection{Effect of Initial Dye Concentration}

Batch mode experiments ( $4 \mathrm{~h}, \mathrm{pH}$ 6, 240 RPM shaking speed, and $0.1 \mathrm{~g}$ adsorbent dosage) were carried out to investigate the influence of the initial concentration of safranin dye (1-100 mg/L), as shown in Figure 7. The dye removal percentage decreased with increasing initial dye concentration, while an opposite trend was observed for the adsorption capacity. The adsorption capacity of CBC600 increased from 1.00 to $17.0 \mathrm{mg} / \mathrm{g}$ and dye removal (\%) decreased from $99.8 \%$ to $17.0 \%$ with increasing dye concentration from 5 to $100 \mathrm{mg} / \mathrm{L}$, as shown in Figure $7 \mathrm{a}, \mathrm{b}$. The dye adsorption capacity $\left(q_{e}\right)$ increased with increasing dye concentration because at an initial high dye concentration, there will be a large number of dye molecules present for a fixed number of adsorbent sites [28]. An 
important parameter, the available surface area, appears to be an important link between the adsorbate concentration and adsorption capacity [23]. The higher available surface area in CBC600 played a major role in the higher adsorption capacity than other adsorbents. At an initial low concentration, safranin will adsorb onto the surface until equilibrium. A previous study reported that the adsorption sites in an adsorbent are fixed for a certain adsorbent mass [44]. Therefore, at high initial safranin concentrations, there will be unadsorbed dye molecules that are not adsorbed due to the lack of adsorption sites [23].
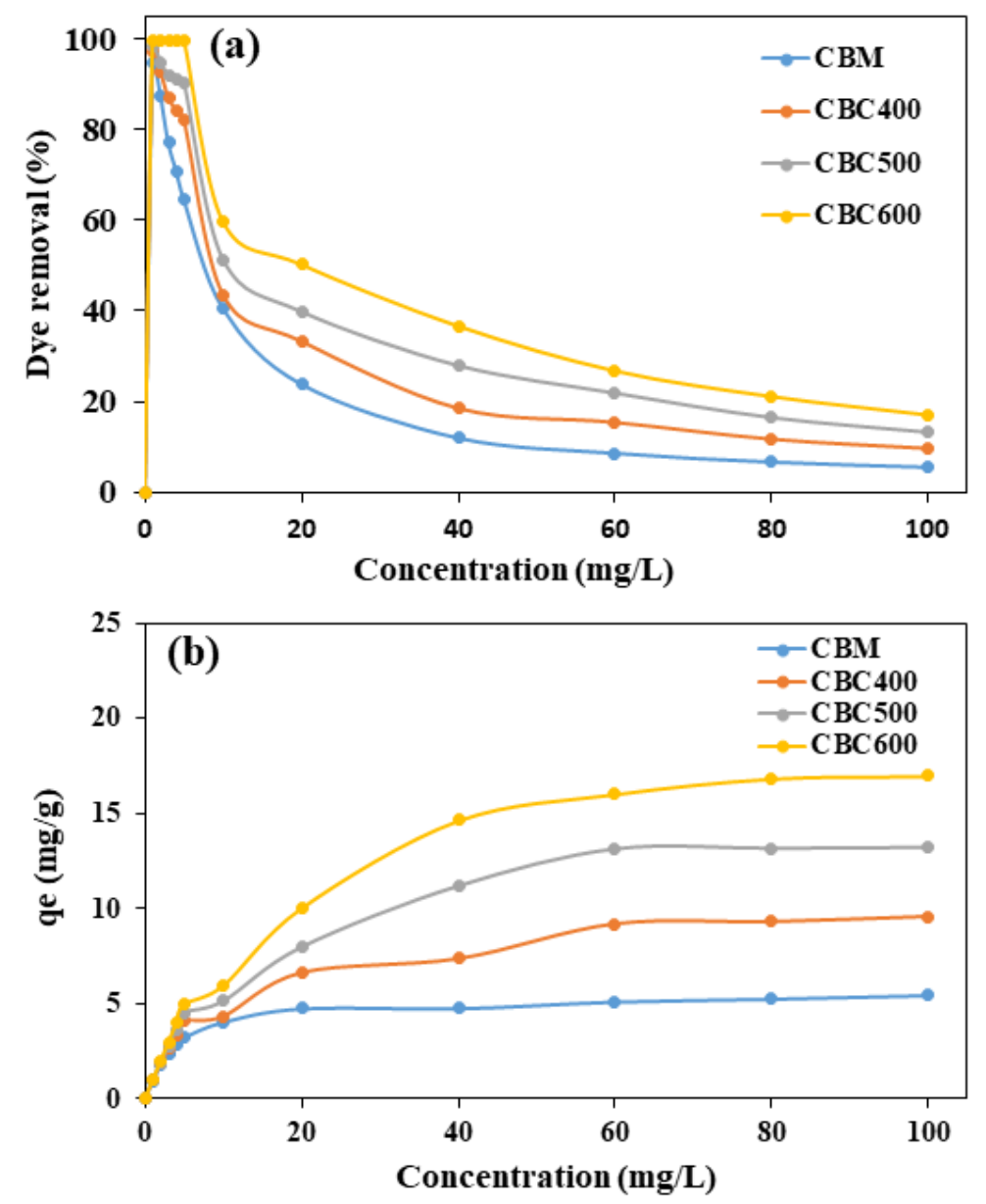

Figure 7. Effect of the initial dye concentration on (a) dye removal (\%) and (b) adsorption capacity.

High dye removal (\%) was observed at low safranin dye concentrations (Figure 7a) because higher adsorption sites are available at low dye concentrations. On the other hand, the situation becomes interesting at high initial dye concentrations because the dye molecules will compete for a fixed number of sites, resulting in unadsorbed dye molecules present in the solution giving rise to a lower dye removal percentage at a high initial dye concentration [30]. Aroguz et al. [45] reported a similar trend for the dye removal percentage. Dye removal decreased from $68.3 \%$ to $47.5 \%$ as the methylene blue concentration was increased from 10 to $60 \mathrm{mg} / \mathrm{L}$.

\subsection{Effect of Adsorbent Dose}

Proper selection of the adsorbent dosage has been considered to play an important role in controlling the adsorption process efficiency because it is related directly to the surface area and sites available for adsorption [30]. The influence of the adsorbent dose on the uptake of safranin dye adsorption was investigated using the initial dye concentration of $5 \mathrm{mg} / \mathrm{L}$, contact time of $4 \mathrm{~h}, \mathrm{pH} 6$, and an adsorbent dose of 0.05 to $0.25 \mathrm{~g}$. A similar reverse trend was observed for the adsorbent dosage as in the case of the initial metal 
concentration for dye removal (\%) and adsorption capacity $\left(q_{e}\right)$. In this experiment, the dye molecule concentration was fixed. The adsorbent dosage was increased, and dye removal (\%) remained relatively unchanged for adsorbent dosages of $>0.1 \mathrm{~g}$. On the other hand, an increase in adsorption capacity was observed until an adsorbent dosage of $0.5 \mathrm{~g}$ and a sharp decrease in adsorption capacity occurred for dosages of $>0.1 \mathrm{~g}$. Dye removal was increased from $52.9 \%$ to $99.7 \%$ and the adsorption capacity decreased from 5.29 to $1.99 \mathrm{mg} / \mathrm{g}$ with increasing adsorbent dosage from 0.05 to $0.25 \mathrm{~g}$, as shown in Figure 8 . The experimental results indicate that $\mathrm{Ce}$ (equilibrium concentration) remained fixed for adsorbent dosages of $>0.1 \mathrm{~g}$, which explains the many unadsorbed sites with increasing adsorbent dosage. Therefore, dye removal remains the same after a certain dosage, and the adsorption capacity starts decreasing with increasing adsorbent dosage [30]. The decrease in adsorption capacity can also be linked to the remaining vacant adsorption sites after dye adsorption [46].
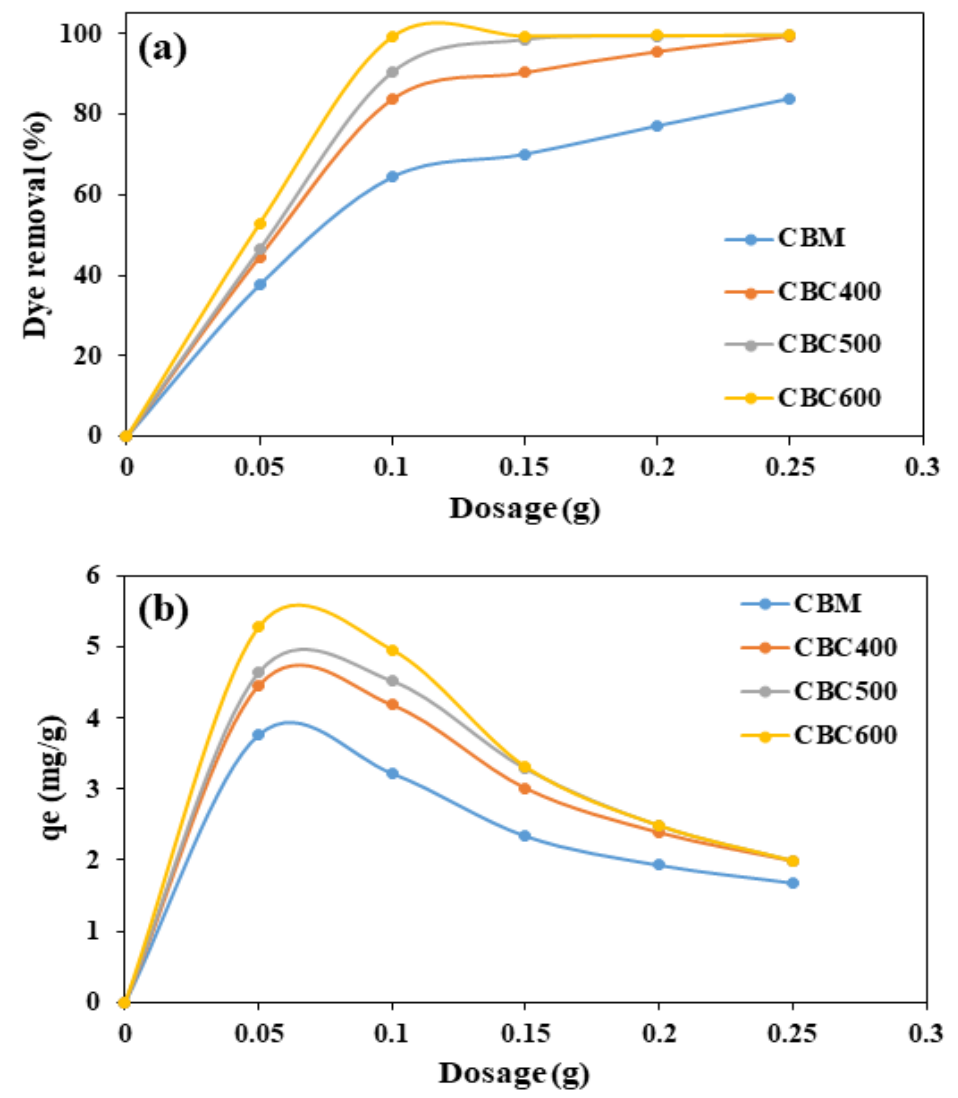

Figure 8. Effect of the dosage on (a) dye removal (\%) and (b) adsorption capacity.

\subsection{Adsorption Isotherms}

The relationship between the amount of safranin dye present in bulk and adsorbed was investigated by considering the adsorption isotherm study. Dye concentrations ranging from 1 to $100 \mathrm{mg} / \mathrm{L}$ were employed to analyze the Langmuir and Freundlich isotherm models, as shown in Figure 9, at an initial pH of 6.0 and adsorbent dosage of $0.1 \mathrm{~g}$. The monolayer adsorption capacity exhibited the following trend: CBC600 > CBC500 > CBC400 > CBM. CBC600 (17.1 mg/g), and CBC500 (13.4 mg/g) exhibited the maximum adsorbent capacity for the removal of dye molecules [47]. 


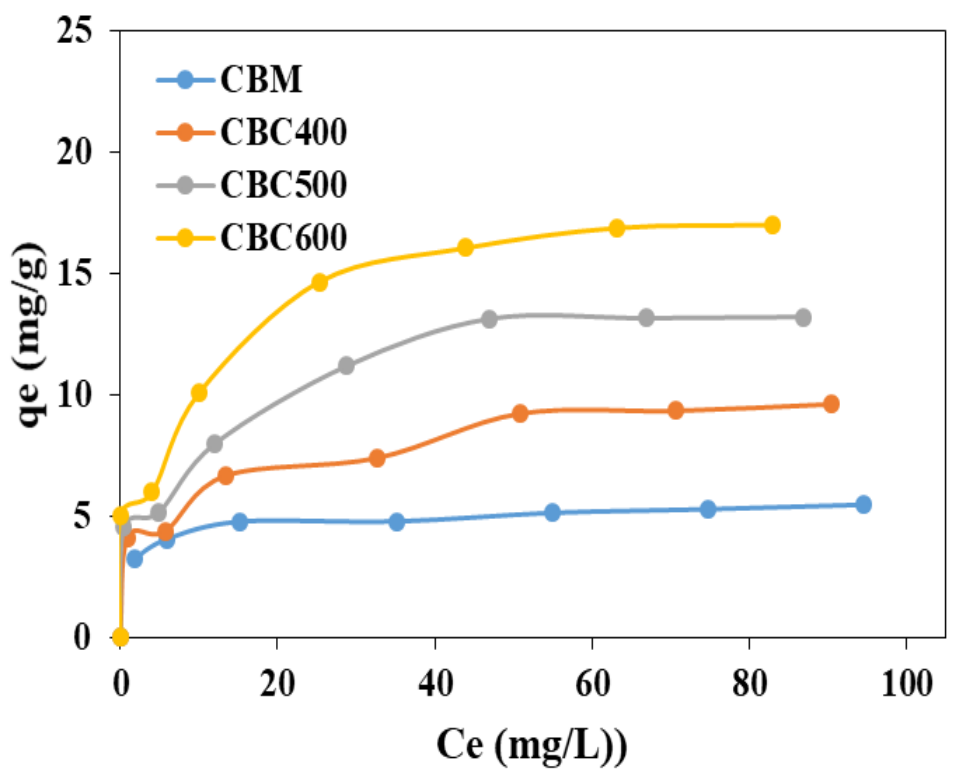

Figure 9. Adsorption isotherm for $\mathrm{CBM}$ and $\mathrm{CBCs}$.

Isotherm study data were fitted in the Langmuir isotherm model equation:

$$
\frac{C_{e}}{q_{e}}=\frac{C_{e}}{q_{\max }}+\frac{1}{K_{L} q_{\max }}
$$

The linearized form of the equation is shown below:

$$
y=m x+c
$$

The calculation of the parameter in equation 5 was deduced from the slope and intercept of the linear equation, as shown in Table 2. $q_{\max }$ and $K_{L}$ were obtained by plotting a graph of $\left(C_{e} / q_{e}\right)$ vs. $\left(C_{e}\right)$, as shown in Figure 10 , where $C_{e}(\mathrm{mg} / \mathrm{L}), q_{e}(\mathrm{mg} / \mathrm{g}),\left(q_{\max }\right)$, and $\left(K_{L}\right)$ are the adsorbent equilibrium concentration, equilibrium adsorbent capacity, and maximum adsorbent uptake, indicating the site saturation, and the Langmuir constant. The equation quantitatively represents the attraction between the safranin dye components and the $\mathrm{CBCs}$ and considers that each safranin dye molecule is adsorbed at a single adsorbent site.

Table 2. Langmuir and Freundlich isotherm parameters for safranin dye onto CBM and CBCs.

\begin{tabular}{cccccc}
\hline Model & Parameters & CBM & CBC400 & CBC500 & CBC600 \\
\hline \multirow{4}{*}{ Langmuir } & $q_{\max }(\mathrm{mg} / \mathrm{g})$ & 5.38 & 9.57 & 13.4 & 17.1 \\
& $K_{\mathrm{L}}(\mathrm{L} / \mathrm{mg})$ & 0.0454 & 0.025 & 0.018 & 0.0143 \\
& $\mathrm{R}_{\mathrm{L}}$ & 0.18 & 0.28 & 0.354 & 0.411 \\
& $\mathrm{R}^{2}$ & 0.998 & 0.9902 & 0.9903 & 0.9905 \\
\hline \multirow{3}{*}{ Freundlich } & $K_{F}(\mathrm{mg} / \mathrm{g})$ & 4.71 & 3.81 & 3.46 & 4.95 \\
& $\mathrm{n}$ & 2.363 & 3.1787 & 4.0289 & 6.9351 \\
& $\mathrm{R}^{2}$ & 0.9265 & 0.9625 & 0.9642 & 0.8844 \\
\hline
\end{tabular}




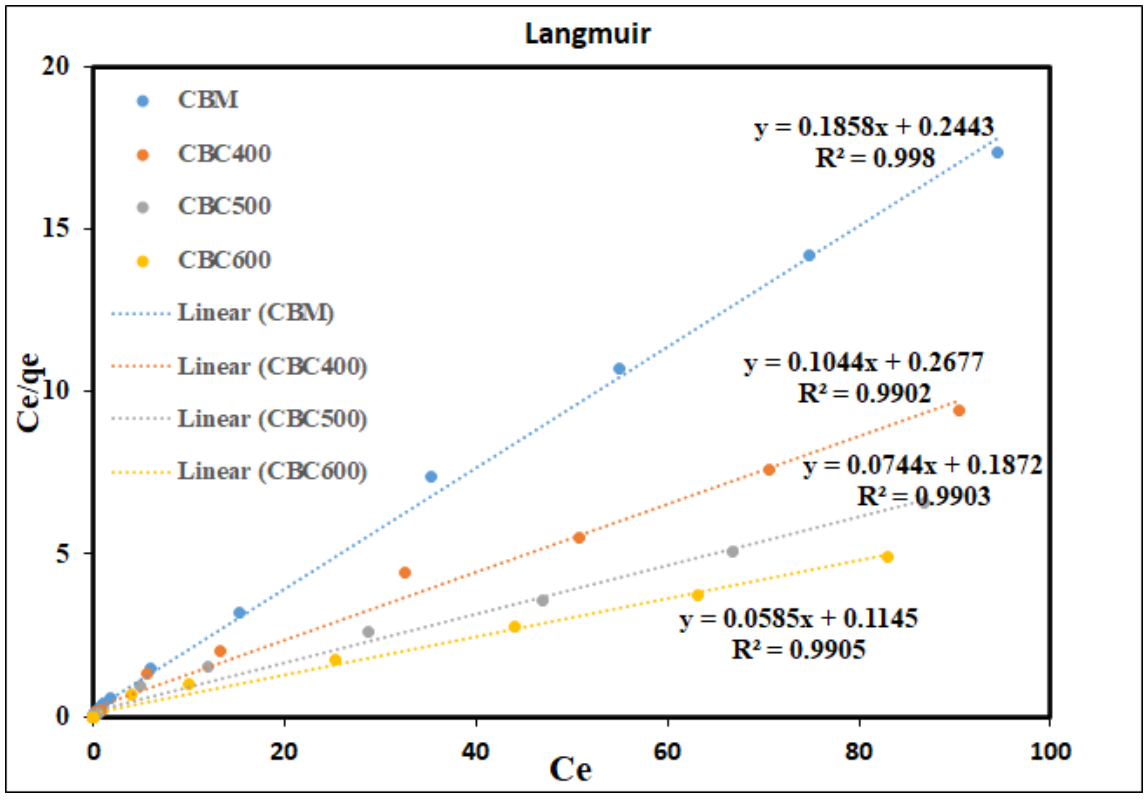

Figure 10. Langmuir isotherm model for the adsorption of safranin on CBM and CBC adsorbents.

Another critical factor $\left(R_{L}\right)$ was also calculated for the Langmuir isotherm, along with $R^{2}$, using Equation (7):

$$
R_{L}=\frac{1}{1+K_{L} C_{o}}
$$

where $C_{o}$ is the safranin initial concentration $(\mathrm{mg} / \mathrm{L}) .\left(R_{L}\right)$ is a dimensionless separation factor characteristic of the Langmuir isotherm that is used to define the affinity between an adsorbent and adsorbate. The $R_{L}$ showed that the Langmuir isotherm is favorable if $0<R_{L}>1$, linear if $R_{L}=1$, unfavorable if $R_{L}>1$, and irreversible of $R_{L}=0$. The experimental data (Table 1) exhibited $R_{L}$ values of $<1$ and $>0$, suggesting that the CBCs are promising adsorbents for the adsorption processes.

The Freundlich isotherm model presumes that adsorption is not restricted to the monolayer and considers multilayer adsorption to uptake metals and dyes. The linear form of the Freundlich equation is given as follows:

$$
\ln q_{e}=\ln K_{F}+\frac{1}{\mathrm{n}} \ln C_{e}
$$

$K_{F}(\mathrm{mg} / \mathrm{g})$ is the constant of the Freundlich isotherm, and $\mathrm{n}$ is a heterogeneity factor, representing the effect of the adsorption capacity and adsorption intensity. The values of these constants are determined by plotting a graph of $\ln q_{e}$ vs. $\ln C_{e}$, as shown in Figure 11. The values in the isotherm for ( $n$ ) showed the following: if $n>1$, a favorable and physical process; $\mathrm{n}<1$, an unfavorable and chemical process; $(\mathrm{n})=1$ is linear. Considering the Freundlich data, from the values of $n$, it is evident that the reaction/isotherm is favorable because $\mathrm{n}>1$ (Table 2). The $K_{F}$ values further confirm the favorability of the safranin concentration on the CBC adsorbents. The Langmuir isotherm model for CBC600 $\left(R^{2}=0.9905\right)$ and CBC500 $\left(R^{2}=0.9903\right)$ was compatible for safranin adsorption because of a more homogeneous surface and monolayer formation compared to CBC600 $\left(R^{2}=0.8844\right)$ and CBC500 $\left(R^{2}=0.9642\right)$ for the Freundlich isotherm, as shown in Table 2. 


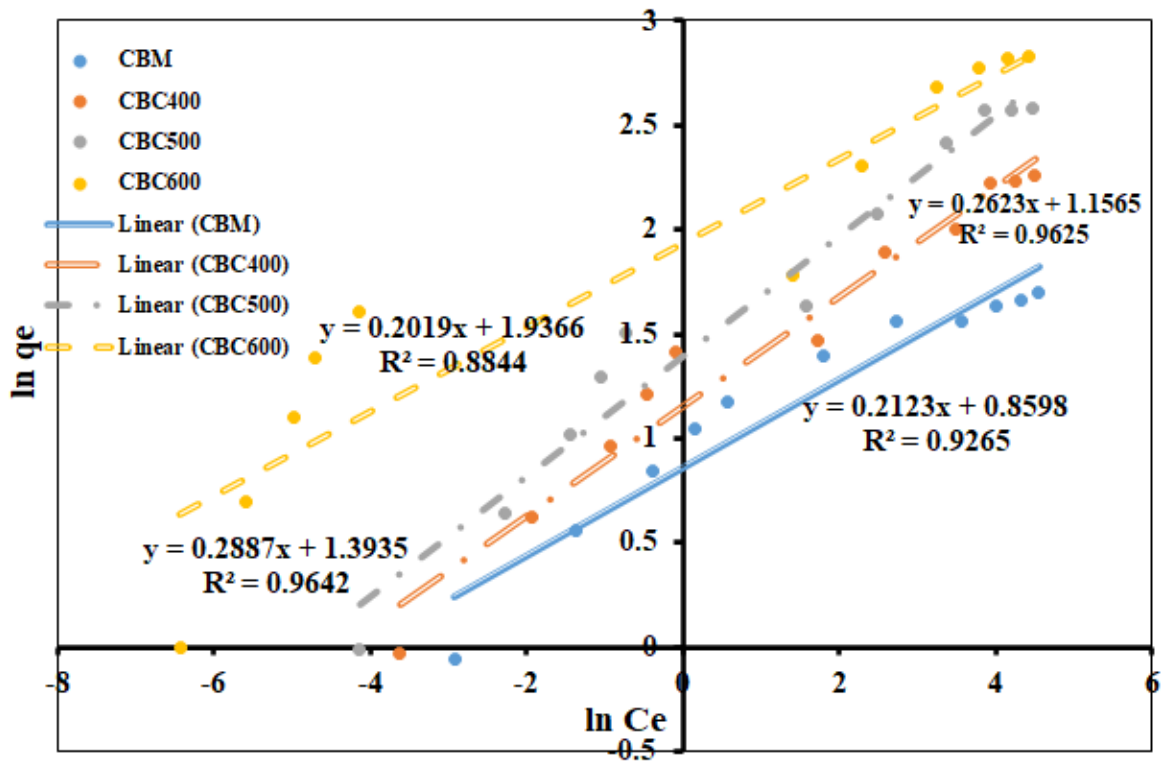

Figure 11. Freundlich isotherm model for the adsorption of safranin on CBM and CBC adsorbents.

\subsection{Adsorption Kinetics}

The kinetics of safranin adsorption from aqueous solutions was determined for all the adsorbents by varying the agitation times, ranging from 1 to $240 \mathrm{~min}$. Pseudo-first-order (PFO), pseudo-second-order (PSO), and intra-particle diffusion (IPD) kinetic models were employed to understand the adsorption mechanism.

The Lagergren first-order rate constant $\left(k_{1}, \mathrm{~min}^{-1}\right)$ in the PFO kinetic model is determined from a linear plot of $\ln \left(q_{e}-q_{t}\right)$ vs. $(t)$, as shown in Figure 12, and the linear form of the Lagergren rate equation is described by equation 9 below [48]:

$$
\ln \left(q_{e}-q_{t}\right)=\ln q_{e}-k_{1} t
$$

where $q_{t}$ is the adsorption capacity of safranin $(\mathrm{mg} / \mathrm{g})$ at any time $(t)$, and $q_{e}(\mathrm{mg} / \mathrm{g})$ is the equilirbrium adsorption capacity. The values of the correlation coefficient $\left(R^{2}\right)$ for different adsorbents are in the range of $0.936-0.9708$, as descirbed in Table 3.

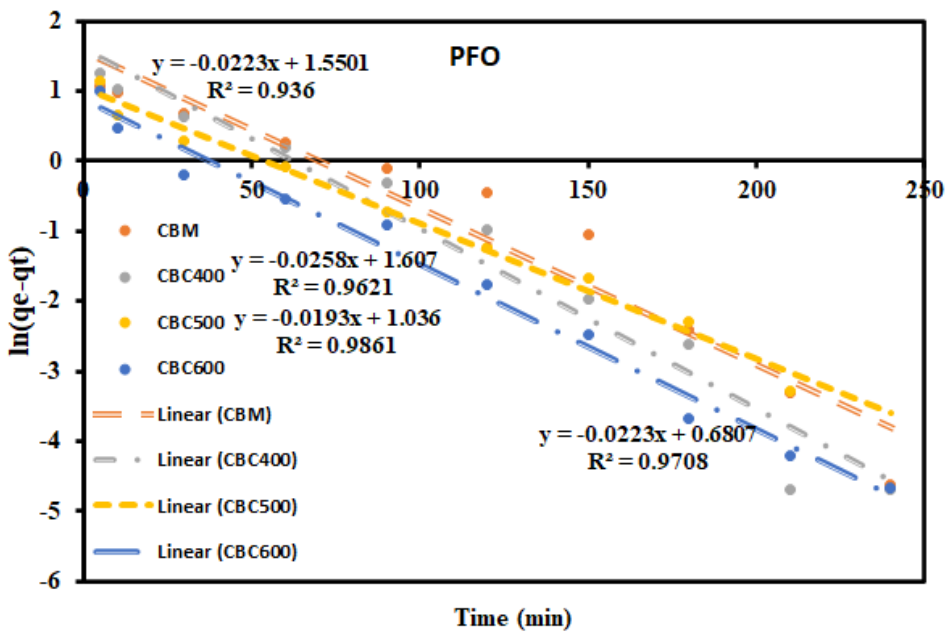

Figure 12. Pseudo-first-order kinetic model for the adsorption of safranin on CBM and CBC adsorbents. 
Table 3. Kinetic model parameters of the pseudo-first-order, pseudo-second-order, and intra-particle diffusion models.

\begin{tabular}{cccccc}
\hline Model & Parameters & CBM & CBC400 & CBC500 & CBC600 \\
\hline \multirow{2}{*}{ Pseudo-first-order } & $k_{1}$ & 0.022 & 0.025 & 0.012 & 0.022 \\
model & $q e$ & 4.21 & 4.98 & 1.8 & 1.98 \\
& $\mathrm{R}^{2}$ & 0.936 & 0.9621 & 0.9861 & 0.9708 \\
\hline \multirow{2}{*}{ Pseudo-second-order } & $k_{2}$ & 1.19 & 4.35 & 9.69 & 23.1 \\
model & $q e$ & 3.79 & 4.57 & 4.66 & 5.08 \\
& $\mathrm{R}^{2}$ & 0.9624 & 0.9902 & 0.9972 & 0.9991 \\
\hline Intra-particle & $k_{P i}$ & 0.23 & 2.14 & 1.90 & 1.7 \\
diffusion model & $\mathrm{C}$ & 0.011 & 0.439 & 1.132 & 1.768 \\
& $\mathrm{R}^{2}$ & 0.9839 & 0.9436 & 0.8508 & 0.7394 \\
\hline
\end{tabular}

The PSO kinetic model linear form described in equaiton 10 is based on the adsorption capacity of the solid phase [48]:

$$
\frac{t}{q t}=\frac{1}{k_{2} q e^{2}}+\frac{1}{q e} \cdot t
$$

$k_{2}$ is the PSO rate constant $(\mathrm{g} / \mathrm{mg}$. $\mathrm{min})$ and determined by plotting the graph of $\left(t / q_{t}\right)$ vs. time $(t)$, a straight line, confirming that the adsorption followed the PSO model, as depicted in Figure 13, and showing a correlation coefficient close to unity $\left(R^{2}=0.9624-0.9991\right)$.

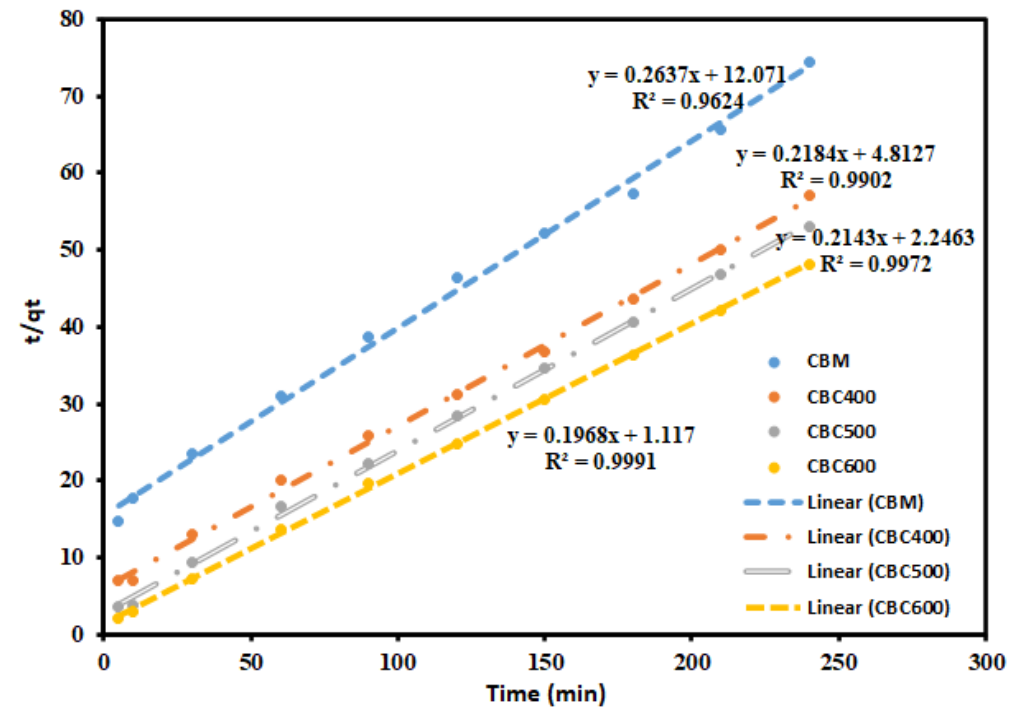

Figure 13. Pseudo-second-order kinetic model for the adsorption of safranin on CBM and CBC adsorbents.

The intra-particle diffusion model is shown in mathematical form in Equation (11) below [23]:

$$
q_{t}=k_{p i} t^{1 / 2}+C
$$

where $C(\mathrm{mg} / \mathrm{g})$ is the boundary layer thickness, and $k_{p i}\left(\mathrm{mg} /\left(\mathrm{g} \cdot \min ^{1 / 2}\right)\right)$ is the IPD rate constant determined from the slope of the linear plot of $\left(q_{t}\right)$ vs. $\left(t^{0.5}\right)$ (Figure 14), and correlation coefficients $\left(R^{2}\right)$ for the IPD model are in the range between 0.7394 and 0.9839 , as described in Table 3. 


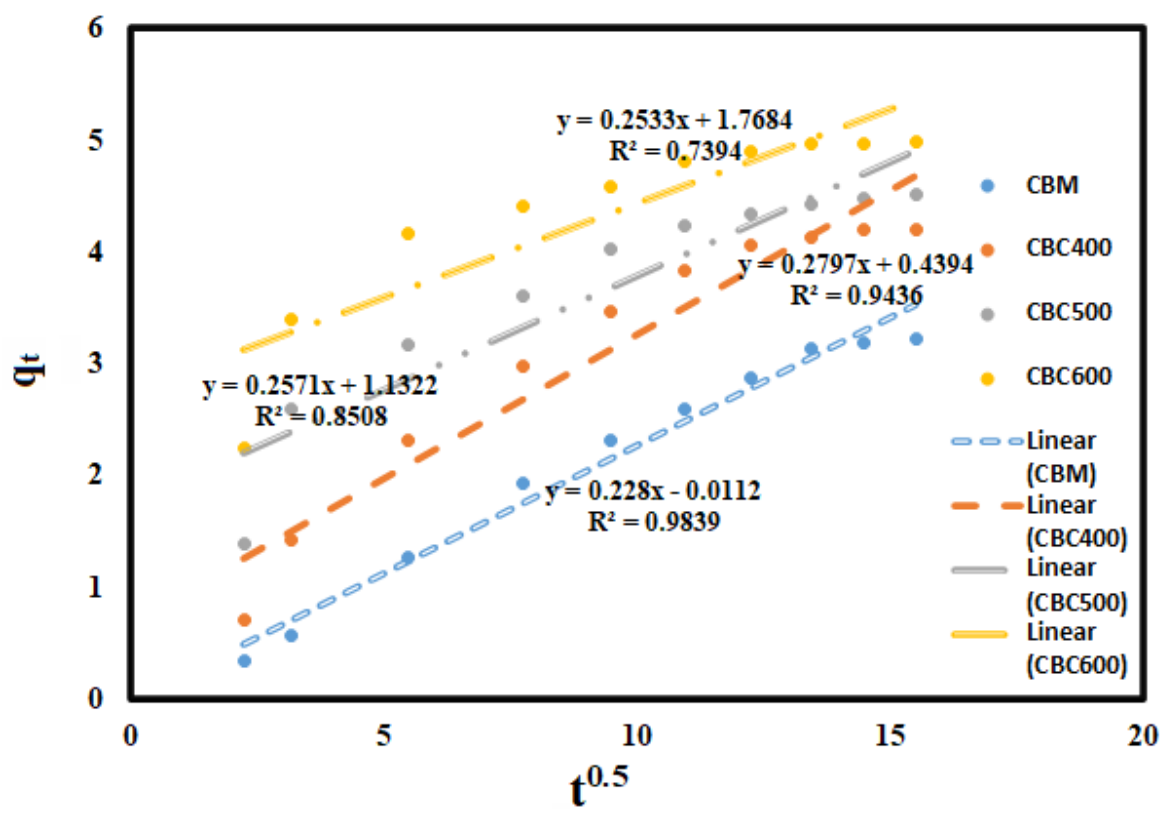

Figure 14. Intra-particle diffusion model for the adsorption of safranin on CBM and CBC adsorbents.

The kinetic plots for the CBC adsorbents for different kinetic models indicate that correlation coefficients for the PSO kinetic models were above 0.99 and led to the conclusion that safranin adsorption on CBC adsorbents obeys the pseudo-second-order kinetic model [49].

\subsection{Adsorbent Regeneration}

The spent adsorbents were regenerated with the application of $\mathrm{HNO}_{3}$ to produce more cost-effective and functional materials. After the regeneration cycles, safranin dye removal (\%) for CBM, CBC400, CBC500, and CBC600 was reduced from $48.5 \%$ to $12.3 \%$, $71.9 \%$ to $43.7 \%, 79.9 \%$ to $51.2 \%$, and $83.6 \%$ to $65.1 \%$, respectively, as shown in Figure 15 . CBC reclamation showed physicochemical changes that ultimately enhanced the effect of safranin dye adsorption. Figure 15 shows that CBC600 and CBC500 exhibited a reversible adsorption process. This regenerative cycle indicates that $\mathrm{CBC}$ adsorbents can be regenerated and recycled for the uptake of safranin, and the adsorption cycle can be repeated many times.

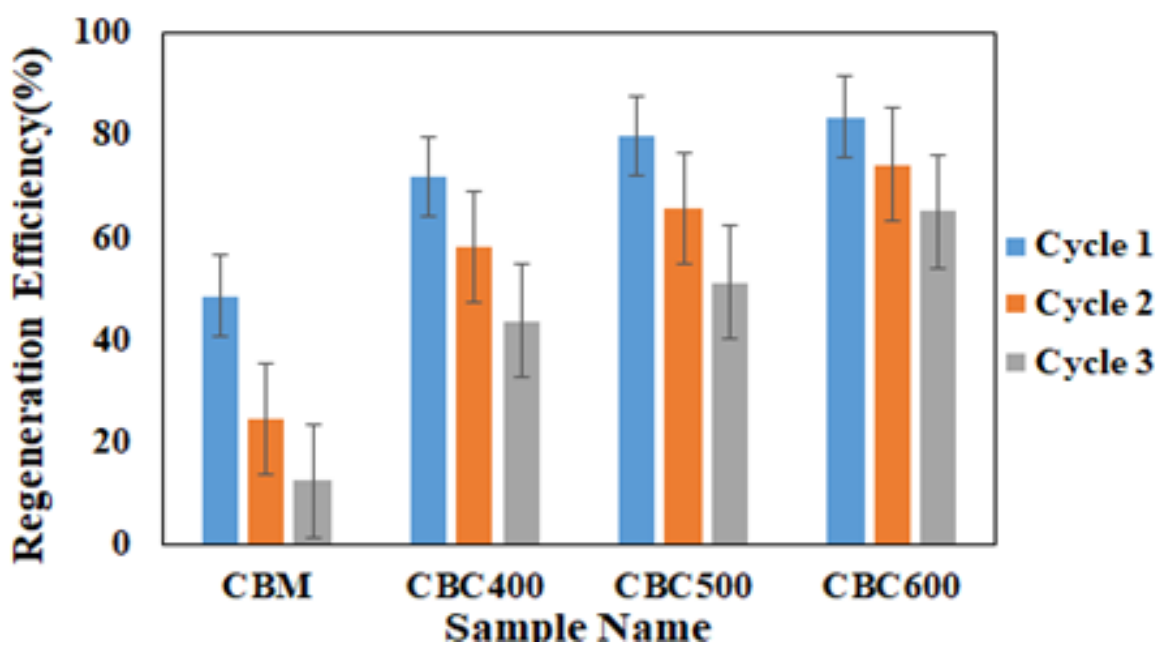

Figure 15. Regeneration efficiencies of adsorbents after three cycles. 


\section{Conclusions}

In this paper, the ability of castor biomass-based biochar synthesized by slow pyrolysis to remove safranin dye from textile wastewater was investigated. The pyrolysis temperature was reported to be an essential parameter for synthesizing biochar adsorbents with excellent performance. Higher pyrolysis temperatures $\left(600^{\circ} \mathrm{C}\right)$ influenced biochar formation with a higher surface area, average pore size, and pore volume. The highest dye removal efficiency of $\mathrm{CBC} 600$ biochar observed was $99.6 \%$, with an adsorption capacity of $4.98 \mathrm{mg} / \mathrm{g}$. An analysis of the adsorption isotherms and adsorption kinetics showed that the experimental data were best fitted to the Langmuir isotherm model $\left(R^{2}=0.9905\right)$ and PSO model $\left(R^{2}=0.9991\right)$ for the adsorption of safranin on CBCs. The maximum monolayer adsorption capacity $\left(q_{\max }\right)$ was calculated to be $17.10 \mathrm{mg} / \mathrm{g}$ for CBC600 compared to the other adsorbents. After three regeneration cycles, the dye removal efficiency of CBC600 was $64.10 \%$, which was high and better than the other castor leaf adsorbents studied. In conclusion, safranin dye from textiles can be removed efficiently from wastewater by applying a castor-based biochar adsorbent synthesized by slow pyrolysis at high temperatures.

Author Contributions: M.S., M.Z., and A.A. developed the conceptualization and methodology of the study. M.U.R. and Y.-K.P. managed resources and provided supervision and valuable research insights into the study. S.H. and A.R. provided literature resources and helped in analysis. N.A.M., T.F. and B.H. contributed to the writing and provided valuable research insights. All authors have read and agreed to the published version of the manuscript.

Funding: The support from the National Research Foundation of Korea under the projects (NRF2020R1I1A1A01072793, NRF- 2020M1A2A2079801) is gratefully acknowledged.

Institutional Review Board Statement: Not applicable.

Informed Consent Statement: Not applicable.

Data Availability Statement: Data are provided within the article.

Conflicts of Interest: The authors declare no conflict of interest.

\section{References}

1. Moogi, S.; Nakka, L.; Potharaju, S.S.P.; Ahmed, A.; Farooq, A.; Jung, S.C.; Rhee, G.H.; Park, Y.K. Copper promoted Co/MgO: A stable and efficient catalyst for glycerol steam reforming. Int. J. Hydrogen Energy 2020, 46, 18073-18084. [CrossRef]

2. Abu Bakar, M.S.; Ahmed, A.; Jeffery, D.M.; Hidayat, S.; Sukri, R.S.; Mahlia, T.M.I.; Jamil, F.; Khurrum, M.S.; Inayat, A.; Moogi, S.; et al. Pyrolysis of solid waste residues from Lemon Myrtle essential oils extraction for bio-oil production. Bioresour. Technol. 2020, 123913. [CrossRef]

3. Bordoloi, N.; Dey, M.D.; Mukhopadhyay, R.; Kataki, R. Adsorption of Methylene blue and Rhodamine B by using biochar derived from Pongamia glabra seed cover. Water Sci. Technol. 2018, 77, 638-646. [CrossRef]

4. Khataee, A.; Gholami, P.; Kalderis, D.; Pachatouridou, E.; Konsolakis, M. Preparation of novel CeO2-biochar nanocomposite for sonocatalytic degradation of a textile dye. Ultrason. Sonochem. 2018, 41, 503-513. [CrossRef]

5. Yaseen, D.; Scholz, M. Textile dye wastewater characteristics and constituents of synthetic effluents: A critical review. Int. J. Environ. Sci. Technol. 2019, 16, 1193-1226. [CrossRef]

6. Attallah, O.; Mamdouh, W. Development and optimization of pectin/chitosan magnetic sponge for efficient cationic dyes removal using Box-Behnken design. Int. J. Environ. Sci. Technol. 2020, 18, 131-140. [CrossRef]

7. Abdullah, A.; Ahmed, A.; Akhter, P.; Razzaq, A.; Hussain, M.; Hossain, N.; Abu Bakar, M.S.; Khurram, S.; Majeed, K.; Park, Y.K. Potential for sustainable utilisation of agricultural residues for bioenergy production in Pakistan: An overview. J. Clean. Prod. 2020, 125047. [CrossRef]

8. Amin, M.; Alazba, A.; Shafiq, M. Comparative study for adsorption of methylene blue dye on biochar derived from orange peel and banana biomass in aqueous solutions. Environ. Monit. Assess. 2019, 191, 1-14. [CrossRef] [PubMed]

9. Fazal, T.; Mushtaq, A.; Rehman, F.; Khan, A.U.; Rashid, N.; Farooq, W.; Rehman, M.S.U.; Xu, J. Bioremediation of textile wastewater and successive biodiesel production using microalgae. Renew. Sustain. Rev. 2018, 82, 3107-3126. [CrossRef]

10. Vijayakumar, G.; Tamilarasan, R.; Dharmendirakumar, M. Adsorption, Kinetic, Equilibrium and Thermodynamic studies on the removal of basic dye Rhodamine-B from aqueous solution by the use of natural adsorbent perlite. J. Mater. Environ. Sci 2012, 3, 157-170.

11. Mullerova, S.; Baldikova, E.; Prochazkova, J.; Pospiskova, K.; Safarik, I. Magnetically modified macroalgae Cymopolia barbata biomass as an adsorbent for safranin O removal. Mater. Chem. Phys. 2019, 225, 174-180. [CrossRef] 
12. Berez, A.; Schäfer, G.; Ayari, F.; Trabelsi-Ayadi, M. Adsorptive removal of azo dyes from aqueous solutions by natural bentonite under static and dynamic flow conditions. Int. J. Environ. Sci. Technol. 2016, 13, 1625-1640. [CrossRef]

13. Namasivayam, C.; Radhika, R.; Suba, S. Uptake of dyes by a promising locally available agricultural solid waste: Coir pith. Waste Manag. 2001, 21, 381-387. [CrossRef]

14. Namasivayam, C.; Arasi, D. Removal of congo red from wastewater by adsorption onto waste red mud. Chemosphere 1997, 34, 401-417. [CrossRef]

15. Bhattacharyya, K.G.; Sarma, A. Adsorption characteristics of the dye, Brilliant Green, on Neem leaf powder. Dyes Pigments 2003, 57, 211-222. [CrossRef]

16. Lorenc-Grabowska, E.; Gryglewicz, G. Adsorption characteristics of Congo Red on coal-based mesoporous activated carbon. Dyes Pigments 2007, 74, 34-40. [CrossRef]

17. Özcan, A.S.; Özcan, A. Adsorption of acid dyes from aqueous solutions onto acid-activated bentonite. J. Colloid Interface Sci. 2004, 276, 39-46. [CrossRef]

18. Ho, Y.-S.; Chiang, T.-H.; Hsueh, Y.-M. Removal of basic dye from aqueous solution using tree fern as a biosorbent. Process Biochem. 2005, 40, 119-124. [CrossRef]

19. Ho, Y.-S.; McKay, G. Sorption of dye from aqueous solution by peat. Chem. Eng. J. 1998, 70, 115-124. [CrossRef]

20. Ayati, A.; Shahrak, M.N.; Tanhaei, B.; Sillanpää, M. Emerging adsorptive removal of azo dye by metal-organic frameworks. Chemosphere 2016, 160, 30-44. [CrossRef] [PubMed]

21. Kalinke, C.; Mangrich, A.S.; Marcolino-Junior, L.H.; Bergamini, M.F. Biochar prepared from castor oil cake at different temperatures: A voltammetric study applied for $\mathrm{Pb} 2+, \mathrm{Cd} 2+$ and $\mathrm{Cu} 2+$ ions preconcentration. J. Hazard. Mater. 2016, 318, 526-532. [CrossRef] [PubMed]

22. Nsami, J.N.; Mbadcam, J.K. The Adsorption Efficiency of Chemically Prepared Activated Carbon from Cola Nut Shells by ZnCl 2 on Methylene Blue. J. Chem. 2013, 2013, 469170.

23. Fazal, T.; Faisal, A.; Mushtaq, A.; Hafeez, A.; Javed, F.; Din, A.A.; Rashid, N.; Aslam, M.; Rehman, M.S.U.; Rehman, F. Macroalgae and coal-based biochar as a sustainable bioresource reuse for treatment of textile wastewater. Biomass Convers. Biorefinery 2019, 1-16. [CrossRef]

24. Huang, Q.; Song, S.; Chen, Z.; Hu, B.; Chen, J.; Wang, X. Biochar-based materials and their applications in removal of organic contaminants from wastewater: State-of-the-art review. Biochar 2019, 1, 45-73. [CrossRef]

25. Ahmed, A.; Abu Bakar, M.S.; Hamdani, R.; Park, Y.K.; Lam, S.S.; Sukri, R.S.; Hussain, M.; Majeed, K.; Phusunti, N.; Jamil, F.; et al. Valorization of underutilized waste biomass from invasive species to produce biochar for energy and other value-added applications. Environ. Res. 2020, 186, 109596. [CrossRef] [PubMed]

26. Srivatsav, P.; Bhargav, B.S.; Shanmugasundaram, V.; Arun, J.; Gopinath, K.P.; Bhatnagar, A. Biochar as an Eco-Friendly and Economical Adsorbent for the Removal of Colorants (Dyes) from Aqueous Environment: A Review. Water 2020, $12,3561$. [CrossRef]

27. Hilioti, Z.; Michailof, C.; Valasiadis, D.; Iliopoulou, E.; Koidou, V.; Lappas, A. Characterization of castor plant-derived biochars and their effects as soil amendments on seedlings. Biomass Bioenergy 2017, 105, 96-106. [CrossRef]

28. Makeswari, M.; Santhi, T. Use of Ricinus communis leaves as a low-cost adsorbent for removal of Cu(II) ions from aqueous solution. Res. Chem. Intermed. 2014, 40, 1157-1177. [CrossRef]

29. Boakye, P.; Tran, H.N.; Lee, D.S.; Woo, S.H. Effect of water washing pretreatment on property and adsorption capacity of macroalgae-derived biochar. J. Environ. Manag. 2019, 233, 165-174. [CrossRef]

30. Rehman, M.S.U.; Munir, M.; Ashfaq, M.; Rashid, N.; Nazar, M.F.; Danish, M.; Han, J.-I. Adsorption of Brilliant Green dye from aqueous solution onto red clay. Chem. Eng. J. 2013, 228, 54-62. [CrossRef]

31. Molla Mahmoudi, M.; Nadali, A.; Soheil Arezoomand, H.R.; Mahvi, A.H. Adsorption of cationic dye textile wastewater using Clinoptilolite: Isotherm and kinetic study. J. Text. Inst. 2019, 110, 74-80. [CrossRef]

32. Zazycki, M.A.; Godinho, M.; Perondi, D.; Foletto, E.L.; Collazzo, G.C.; Dotto, G.L. New biochar from pecan nutshells as an alternative adsorbent for removing reactive red 141 from aqueous solutions. J. Clean. Prod. 2018, 171, 57-65. [CrossRef]

33. Geethakarthi, A.; Phanikumar, B. Adsorption of reactive dyes from aqueous solutions by tannery sludge developed activated carbon: Kinetic and equilibrium studies. Int. J. Environ. Sci. Technol. 2011, 8, 561-570. [CrossRef]

34. Ahmad, M.; Rajapaksha, A.U.; Lim, J.E.; Zhang, M.; Bolan, N.; Mohan, D.; Vithanage, M.; Lee, S.S.; Ok, Y.S. Biochar as a sorbent for contaminant management in soil and water: A review. Chemosphere 2014, 99, 19-33. [CrossRef] [PubMed]

35. Chen, Y.; Yang, H.; Wang, X.; Zhang, S.; Chen, H. Biomass-based pyrolytic polygeneration system on cotton stalk pyrolysis: Influence of temperature. Bioresour. Technol. 2012, 107, 411-418. [CrossRef] [PubMed]

36. Keiluweit, M.; Nico, P.S.; Johnson, M.G.; Kleber, M. Dynamic molecular structure of plant biomass-derived black carbon (biochar). Environ. Sci. Technol. 2010, 44, 1247-1253. [CrossRef]

37. Kaal, J.; Cortizas, A.M.; Reyes, O.; Soliño, M. Molecular characterization of Ulex europaeus biochar obtained from laboratory heat treatment experiments-A pyrolysis-GC/MS study. J. Anal. Appl. Pyrolysis 2012, 95, 205-212. [CrossRef]

38. Oudemans, T.; Boon, J.; Botto, R. FTIR and solid-state 13C CP/MAS NMR spectroscopy of charred and non-charred solid organic residues preserved in Roman Iron Age vessels from the Netherlands. Archaeometry 2007, 49, 294-571. [CrossRef]

39. Nandi, B.K.; Goswami, A.; Purkait, M.K. Adsorption characteristics of brilliant green dye on kaolin. J. Hazard. Mater. 2009, 161, 387-395. [CrossRef] 
40. Thitame, P.; Shukla, S. Adsorptive removal of reactive dyes from aqueous solution using activated carbon synthesized from waste biomass materials. Int. J. Environ. Sci. Technol. 2016, 13, 561-570. [CrossRef]

41. Basaleh, A.A.; Al-Malack, M.H.; Saleh, T.A. Methylene Blue removal using polyamide-vermiculite nanocomposites: Kinetics, equilibrium and thermodynamic study. J. Environ. Chem. Eng. 2019, 7, 103107. [CrossRef]

42. Darwish, A.; Rashad, M.; AL-Aoh, H.A. Methyl orange adsorption comparison on nanoparticles: Isotherm, kinetics, and thermodynamic studies. Dyes Pigments 2019, 160, 563-571. [CrossRef]

43. Mane, V.S.; Babu, P.V. Studies on the adsorption of Brilliant Green dye from aqueous solution onto low-cost NaOH treated saw dust. Desalination 2011, 273, 321-329. [CrossRef]

44. Auta, M.; Hameed, B. Acid modified local clay beads as effective low-cost adsorbent for dynamic adsorption of methylene blue. J. Ind. Eng. Chem. 2013, 19, 1153-1161. [CrossRef]

45. Aroguz, A.Z.; Gulen, J.; Evers, R. Adsorption of methylene blue from aqueous solution on pyrolyzed petrified sediment. Bioresour. Technol. 2008, 99, 1503-1508. [CrossRef]

46. Nethaji, S.; Sivasamy, A.; Mandal, A. Adsorption isotherms, kinetics and mechanism for the adsorption of cationic and anionic dyes onto carbonaceous particles prepared from Juglans regia shell biomass. Int. J. Environ. Sci. Technol. 2013, 10, $231-242$. [CrossRef]

47. Shojaei, N.; Aminsharei, F.; Ahangar, H.A. Application of hydrophobic polymers as solidifiers for oil spill cleanup. Int. J. Environ. Sci. Technol. 2020, 18, 1419-1424. [CrossRef]

48. Febrianto, J.; Kosasih, A.N.; Sunarso, J.; Ju, Y.-H.; Indraswati, N.; Ismadji, S. Equilibrium and kinetic studies in adsorption of heavy metals using biosorbent: A summary of recent studies. J. Hazard. Mater. 2009, 162, 616-645. [CrossRef]

49. Sun, D.; Zhang, X.; Wu, Y.; Liu, T. Kinetic mechanism of competitive adsorption of disperse dye and anionic dye on fly ash. Int. J. Environ. Sci. Technol. 2013, 10, 799-808. [CrossRef] 